Llona, M. (coord./ed.); García-Orellán, R.; Roca i Girona, J. I.; Martínez Flores, L; Vilanova, M.; Domínguez Prats, P; Díaz Sánchez, P; Sandoval García, C. (2012). Entreverse, teoría y metodología práctica de las fuentes orales. Bilbao, Universidad del País Vasco / Euskal Herrico Unibersitatea, Servicio Editorial.

\title{
Entreverse, teoría y metodología práctica de las fuentes orales
}

Joan Prat

DAFITS, joan.prat@urv.cat

Entreverse, teoria y metodología práctica de las fuentes orales és un llibre colllectiu que consta de set col-laboracions. Els tres primers capítols — de l'editora Miren Llona, Rosa García-Orellán i Jordi Roca, conjuntament amb Lídia Martínez Flores - tenen un caràcter més aviat teòric, mentre que els quatre restants — signats per Mercedes Vilanova, Pilar Domínguez Prats, Pilar Díaz Sánchez i Carlos Sandoval - són, per la seva temàtica, força més monogràfics.

Després d'un breu pròleg on la coordinadora i editora explica els objectius de la publicació, ella mateixa signa el primer capítol, titulat "Historia oral: la explicación de las identidades a través de la historia de vida”, en el qual aborda un seguit de temàtiques generals com ara el paper de la memòria vista no tant com un magatzem de records, sinó com una instància de caràcter creatiu i fonamental en la construcció del subjecte; la importància dels enclavaments de memòria (allò que Teresa del Valle, que no és mencionada malgrat la proximitat geogràfica, i seguint Bakhtin, anomena cronotopos); els vincles entre memòria individual i col+lectiva i entre passat i present, i les diferències de gènere a l'hora de definir el jo i la pròpia vida. També com els anomenats egodocuments són generats a tres bandes, el narrador, l'entrevistador i la vinculació del narrador amb els discursos culturals del passat i del present, així com altres temes teòrics generals.

L'apartat titulat "La creación de fuentes orales, entrevistar, entre-verse, hablarse, conocerse", a més de donar títol general al llibre - Entreverse-, es dedica a reflexionar sobre el grau o nivell d'intervenció de l'entrevistador/a en el 
procés de construcció de la biografia o autobiografia. Lautora resol el dilema tot recomanant un paper "activament discret".

A "Pautas para entrevistar. Problemas y dificultades en la realización de entrevistas", la Dra. Llona presenta una bateria de pautes que cal seguir en l'abans, durant i després de l'entrevista — curiosament, la mateixa estructura que el Grup de Recerca Biogràfica (GBR) d'aquest Departament vam establir en la monografia "I això és la meva vida..." Relats biogràfics i societat (2004) i que Miren Llona no coneix - i finalitza el capítol amb diferents exemples de persones — totes del gènere femení- entrevistades en diferents moments i que li serveixen per il.lustrar alguns dels plantejaments realitzats prèviament.

El segon article porta per títol "De la oralidad a la intención biográfica" i va signat per Rosa García-Orellán, de qui coneixia una tesi doctoral publicada, Hacia el encuentro de mi anthropos: la muerte dinamo-estructural de la vida (2001), de lectura tan enrevessada com ho és el mateix enunciat. Tampoc la lectura d'aquest capítol no m'ha resultat còmoda. En efecte, a la "Introducción" $i$ als epígrafs rotulats "La corriente naturalista y la biografía" $i$ "Hacia la perspectiva biográfica", l'autora fa una presentació tan sui generis del mètode biogràfic que sovint resulta irrecognoscible segons els paràmetres convencionals (Feixa, 2000; De Miguel, 1996, i Pujadas, 1990. D’aquest darrer autor, García-Orellán cita el clàssic El método biográfico, que sembla no haver llegit).

A la segona part del capítol, aquesta professora a la Universitat Pública de Navarra insisteix que el que ella anomena "la perspectiva biográfica" ha d'inserir-se dins d'un procés investigador més ampli que illlustra amb la seva recerca sobre la pesca a Terranova i publicada en el llibre Hombres de Terranova: la pesca industrial del bacalao (1926-2004).

Altres temes apuntats són els registres de les entrevistes, si cal portar o no un qüestionari previ, la curiositat per la vida dels altres (que García-Orellán denomina amb l'apel.latiu d'extrañamiento), el tema de la veritat o mentida del que expliquen els informants, així com unes darreres reflexiones genèriques sobre memòria i narrativa.

Precisament sobre aquest darrer tema el lector pot gaudir, ara sí, de la lectura de "Mi vida, tu vida, la nuestra. Determinantes y configuración de la estructura narrativa de los relatos de vida", capítol signat pels nostres companys del DAFITS, Jordi Roca i Lídia Martínez Flores, que coneixen bé el tema que porten entre mans. En efecte, el Jordi i la Lídia ja varen fer un bon tàndem a 
la monografia esmentada del Grup de Recerca Biogràfica "I això és la meva vida..." ocupant-se de la darrera part — "el Text"-, on treballaven els relats autobiogràfics des de la perspectiva de l'estructura narrativa. Aquesta mateixa orientació l'han desenvolupada i enriquida en altres ocasions, plegats o per separat, com sespecifica a les notes 1 i 2 del mateix capítol.

La tesi bàsica dels autors és que un relat biogràfic és, fonamentalment, una recreació discursiva que proposa l'informant en la línia de la triple il.lusió biogràfica i que el resultat final es pot abordar des de diferents perspectives. En aquest sentit, són importants la distinció entre societat industrial i postmoderna; els grans eixos o focalitzacions que estructuren el relat (cronològic, temàtic, laboral, familiar, seguint un esdeveniment central, etc.). També analitzen amb cura les distintes maneres i models d'iniciar un relat i acabar-lo; allò que es diu i el que no; el caràcter individual del posttext tenyit, però, de l'empremta collectiva, i totes aquestes reflexions sustentades amb una bibliografia ben seleccionada i posada al dia. El resultat final és un text rigorós i ben estructurat que fa bo de llegir.

Després d'aquests articles orientats teòricament, els segueixen els altres quatre més centrats, com deia, en temàtiques particulars. Aquest és el cas de "Imposturas y claves sobre los republicanos españoles deportados a Mauthausen", capítol signat per Mercedes Vilanova, una referent imprescindible en l'àmbit de la història oral i fundadora i directora, durant molts anys, d'Historia, Antropología y Fuentes Orales. La professora Vilanova, que havia col-laborat en dos projectes internacionals sobre deportats espanyols al camp d'extermini nazi de Mauthausen (un de Gerhard Botz, de la Universitat de Viena, i l'altre d'Alexander von Plato, d'Alemanya) i havia entrevistat un seguit de republicans al llarg i ample de la geografia espanyola, aquí recupera part d'aquest material i l'analitza novament.

Així, i després d'una molt complerta revisió de les fonts catalanes i espanyoles sobre el tema (ben detallades a la nota 5), l'autora selecciona un conjunt de temes que li foren explicats pels seus informants: en primer lloc, les dades personals (origen geogràfic i social, edat, ideologia, oficis), per passar a l'anàlisi de com sobreviure en situacions extremes com ara un camp d'extermini. En el darrer epígraf, titulat "Imposturas y «realismo mágico»", es descriu el cas ben conegut d'Enric Marco, investigat per un historiador "quisquilloso" (en paraules de Vargas Llosa recollides per Vilanova) i que un dia va descobrir la seva 
impostura, és a dir, el fet que mai no havia estat deportat a Mauthausen, com ell havia afirmat des de sempre $i$ als quatre vents.

Els dos articles següents estan protagonitzats per collectius femenins. El primer es titula “"Ellas nos cuentan»: los relatos de vida en la historia del exilio republicano en México" i és de Pilar Domingo Prats, de la Universitat de Las Palmas de Gran Canaria. Es tracta d'una visió panoràmica de l'exili dels republicans a Mèxic amb un èmfasi específic en el col+lectiu de les dones, entre les quals l'autora distingeix ben clarament el grup minoritari d'exiliades intel-lectuals i polititzades del de la majoria apolítica. A l'article es fa un repàs acurat de la bibliografia sobre el tema (tant de la part d'investigadors mexicans com espanyols); l'experiència de la investigadora entrevistant les informants; la interpretació del caràcter polièdric de les entrevistes; les formes d'autorepresentació en els relats orals, així com la "comunitat de memòria" expressada en aquestes paraules precises de Paloma Aguilar: "són els individus els que recorden, però són els grups els que determinen allò que és digne de ser recordat" (traducció meva, p. 179).

La professora Pilar Díaz Sánchez, de l’Autónoma de Madrid, colllabora a Entreverse amb el capítol titulat "Las fuentes orales y la construcción de relatos biográficos: mujeres trabajadoras en la dictadura franquista". A la primera part de l'escrit, l'autora planteja de nou la relació que s'estableix entre entrevistadora i entrevistades i emfatitza la utilitat d'aquesta metodologia per als estudis de gènere i de la història de les dones des d'una perspectiva feminista, i tot això vinculat als corrents historiogràfics interessats per l'estudi de la subalternitat $i$ a fer una "història des de baix".

Pilar Díaz situa les entrevistes orals fetes a les dones entre l'autobiografia i el testimoni i després d'algunes digressions teòriques focalitza l'anàlisi entorn de dones treballadores al si de la dictadura franquista, com senuncia en el títol. Empra els materials emmagatzemats en el fons documental del Seminario de Fuentes Orales M. ${ }^{a}$ Carmen García Nieto de la Universitat Complutense de Madrid. Les testimonis escollides parlen, fonamentalment, de la seva activitat laboral i un epígraf és dedicat a la militància obrera de les dones, ben analitzada des de casos concrets.

El darrer capítol, de Carlos Sandoval García, de la Universitat de Costa Rica, es titula "Contestar la hostilidad antiinmigrante en Costa Rica. Un proyecto de ciencias sociales públicas en curso". El text, ben estructurat, reflexiona 
entorn de tres àrees del debat migratori a Costa Rica: la primera avalua la possibilitat d'incidir en la política pública; la segona s'interroga sobre els imaginaris fortament negatius sobre la immigració dels nicaragüencs i les possibilitats d'influir-hi, i, finalment, la tercera es refereix a la intervenció en comunitats migrants perquè es puguin posicionar enfront dels discursos criminalitzadors que les interpel-len. Aquests tres objectius han estat plantejats en els projectes de recerca de l'Instituto de Investigaciones Sociales de la Universidad de Costa Rica entre els anys 2005 i 2011. La totalitat de l'escrit del doctor Sandoval està orientat cap a uns objectius de tipus pràctic, malgrat que l'autor no s'hi fa gaires il.lusions i conclou així: "No es difícil reconocer que suele haber resistencia mutua entre quienes formulan políticas y quien realizan/mos investigación académica. Esto ocurre, sobre todo, en tiempos como los actuales en que las políticas mantienen una acentuada orientación, en términos generales, neoliberal, y la investigación académica reivindica el análisis crítico" (p. 238).

Un breu currículum de les autores i autors clou el llibre, que en gran manera té les virtuts i els inconvenients de força readings col-lectius. Entre les primeres podríem posar en relleu la varietat d'enfocaments i continguts i entre els inconvenients, la desigual qualitat de les contribucions, les pesades repeticions $i$ redundàncies temàtiques $i$, en aquest cas específic, la promesa inicial de treballar per la interdisciplinarietat, cosa que amb l'excepció de l'article dels nostres companys, Jordi Roca i Lídia Martínez, s'incompleix de manera clara i rotunda, ja que ningú no fa el més petit esforç en aquesta direcció i les fronteres disciplinàries - història oral, sociologia i antropologia — continuen tan rígides com sempre. 